\title{
EDITORIAL
}

\section{Drug discrimination: 30 years of progress}

\author{
Joseph H. Porter • Adam J. Prus
}

Received: 19 January 2009 / Accepted: 22 January 2009/Published online: 19 February 2009

(C) Springer-Verlag 2009

\section{Editorial}

The publication of this Special Issue of Psychopharmacology on the Stimulus Properties of Drugs marks the 30-year anniversary in 2008 of the founding of the Society for Stimulus Properties of Drugs (SSPD). As previously described by the society's first three presidents (see Overton et al. 1999), the decision to create an organization of researchers interested in the discriminative stimulus properties of drugs occurred at a meeting in 1978 of the Federation of American Societies for Experimental Biology (FASEB). The first official meeting of SSPD was held a few months later on June 3, 1978 in conjunction with the meeting of the Committee for Problems on Drug Dependence (CPDD) in Baltimore, MD, USA. SSPD has met annually since then and SSPD's 30th anniversary meeting was held on November 14, 2008 as a satellite meeting at the meeting of the Society for Neuroscience in Washington, D.C.

In addition to the annual national meetings of the society, a number of international meetings have been held since 1978 with the most recent being in 2005 as a satellite meeting of the European Behavioral Pharmacology Society in Barcelona, Spain. There also have been a number of books (often based on these symposia) on the stimulus properties of drugs published over the years (Colpaert and Balster 1988, Colpaert and Slangen 1982, Glennon et al.

J. H. Porter $(\bowtie)$

Department of Psychology, Virginia Commonwealth University, Richmond, VA 23284-2018, USA

e-mail: jporter@vcu.edu

\section{A. J. Prus}

Department of Psychology, Northern Michigan University, Marquette, MI 49855, USA

e-mail: aprus@nmu.edu
1991, Lal 1977, Thompson and Pickens 1971) as well as a collection of articles in Volume 64 (No. 2) of Pharmacology, Biochemistry and Behavior in 1999.

\section{What are the stimulus properties of drugs?}

A very basic definition of a stimulus is something that affects an organism by causing a response. In experimental psychology, stimuli have traditionally been such things as tones, lights, etc., and typically, a laboratory situation would be set up to assess changes in responding that occurred when changes in the stimulus were produced. A stimulus is generally defined by its characteristics, or properties, and again, in a traditional sense, stimulus properties would consist of such things as the frequency of a tone or the intensity of a light. Clearly, drugs also can serve as stimuli and the properties of drug stimuli are mediated by the drug's biological actions on the central nervous system (e.g., functioning as an agonist or an antagonist at a specific neurotransmitter receptor). Much of the early research on the stimulus properties of drugs used the state-dependent paradigm (Overton 1974), but in the 1970s the drug discrimination paradigm was developed (see review by Colpaert 1999). As Colpaert (1999) describes (and the articles in this Special Issue mirror), the drug discrimination paradigm has largely replaced the statedependent paradigm in the study of the stimulus properties of drugs. As Balster (1988) states, "One of the major conceptual advances in behavioral pharmacology was the appreciation that drug effects could subserve stimulus properties in stimulus-response learning theory." Balster also points out that the first major recognition that drugs could function as stimuli and produce responses in organisms was in a collection of articles from the proceedings of a 
conference on the Stimulus Properties of Drugs (Thompson and Pickens 1971). Thus, it has become well accepted that drugs can affect behavior and function as stimuli. While the phrase "stimulus properties of drugs" sometimes has different meanings in drug discrimination studies, it typically refers to the "subjective" effects of drugs or to the underlying neural mechanisms that control the discriminative stimulus properties of drugs (see Balster 1988).

The drug discrimination procedure has been used now for over 40 years and many researchers who use this procedure are members of the Society for Stimulus Properties of Drugs (http://www.sspd.org.uk). According to the SSPD website, the drug discrimination method "is a way for training people or experimental animals to recognize these drug effects and to measure them in a precise, reliable, and quantitative manner. It plays an important role in the science of psychopharmacology and is used in many academic departments of pharmacology, psychology, and neuroscience and in the pharmaceutical industry". Ian Stolerman (Stolerman and Shine 1985, Stolerman et al. 1995; 1989) established and maintains the Drug Discrimination Database (http://www.dd-database. org), which now has over 4,000 drug discrimination references published between 1951 and 2008 (including abstracts, journal articles, book chapters, and books). As described on the Drug Discrimination Database "Ian Stolerman and colleagues at the Institute of Psychiatry, London published the first version of the Drug Discrimination Database in a book recording the proceedings of the second international conference on drug discrimination (Stolerman 1982). At that time there were 427 citations in the database." In 1985 the database web site was established by virtue of a grant from the National Institutes of Drug Abuse (NIDA) and has been continually funded since then by NIDA. The scope of the database has been expanded with the most recent NIDA grant in 2007. The database will now include drug self-administration research and the project name was changed to "Comprehensive Database of Drug Discrimination and Self-administration Research." The new Drug Self-administration Database is in preparation and once it is added (by early 2009) to the website, researchers will be able to search either for drug discrimination references or for drug self-administration references. This database will continue to provide a valuable resource for researchers interested in using the drug discrimination procedure for many years.

\section{Special issue on the stimulus properties of drugs}

The 20 original investigations and three review articles in this Special Issue on the Stimulus Properties of Drugs reflect the diversity and utility of the drug discrimination procedure. While the majority of the studies (11) used rats as subjects, four studies used non-human primates, three studies used mice (including one study with knock-out mice) and one study used human subjects. These articles also display the wide variety of drug classes that are studied with drug discrimination, including cannabinoids, cocaine, hallucinogens, opioids, nicotine, antidepressants, antipsychotics, and others. While many of these studies are probably best characterized as basic research, some of them would be considered translational research (see Woolf 2008) as they attempt to provide a better understanding of therapeutic drugs or drugs that have potential therapeutic efficacy. For example, the discriminative stimulus properties of the atypical antidepressant, mirtazapine, were found to be mediated primarily by antagonism of $5-\mathrm{HT}_{2 \mathrm{C}}$ receptors and, thus, appear to be distinct from other antidepressants such as selective serotonin reuptake inhibitors (Dekeyne and Millan 2009). Another study (Prus et al. 2009) examined the major metabolite, N-desmethylclozapine (NDMC), of the atypical antipsychotic clozapine, as there has been interest in the therapeutic potential NDMC. The study revealed that there were differences in the discriminative stimulus properties of clozapine and NDMC that appeared to reflect the agonist properties of NDMC at $\mathrm{M}_{1}$ muscarinic cholinergic receptors.

Many of these articles also demonstrate how the drug discrimination procedure can be used to provide a better understanding of the underlying receptor pharmacology/ mechanisms of a drug. For example, in the study by Koffarnus et al. 2009) rats were trained to discriminate D2and D3-preferring agonists. Interestingly, tests with selective antagonists suggested that the activation of D2 receptors was responsible for the discriminative stimulus effects of both sumanirole (a D2-preferring agonist) and pramipexole (a D3-preferring agonist) and that activation of D3 receptors appears to play little or no role in the discriminative stimulus properties of these drugs. Drug discrimination procedures can also be used to characterize the pharmacology of novel compounds by comparing them to compounds with known pharmacological actions. In the study by Baker et al. (2009) the drug salvinorin A (which is found in the hallucinogenic plant, Salvia divinorum) was compared to kappa opioid (KOP) receptor ligands. The findings indicated that the discriminative stimulus effects of salvinorin A are mediated by kappa receptors. Given that kappa opioid receptor ligands may have therapeutic potential for the treatment of neuropsychiatric conditions, including drug dependence and mood disorders, these finding suggest that salvinorin A analogs may have potential for use in pharmacotherapy.

The drug discrimination paradigm can also be used to assess the role of environmental variables in the modulation of drug actions. For example, a study on the discriminative stimulus properties of cocaine (Kohut et al. 2009) demonstrates that environmental manipulations can alter the 
animals' response to a drug of abuse. The study found that maternal separation (in a sex-dependent manner) altered both the discriminative stimulus effects of cocaine and the underlying dopamine mechanisms (as measured by changes in Fos expression) that are believed to mediate cocaine's discriminative and abuse properties. Finally, in a unique use of the drug discrimination paradigm (Jewett et al. 2009), rats were trained to discrimination 22 -h of food deprivation from 2-h of food deprivation. Then drugs (sibutramine and rimonabant) that are known to decrease food intake in both human and non-human animals were administered. Sibutramine appeared to decrease food intake by altering the hunger sensation associated with food deprivation; whereas, rimonabant did not change the rats' ability to discriminate the two different food deprivation conditions. While both drugs were able to reduce response rates and food intake, the drug discrimination paradigm identified differences between the two drugs with regard to the sensations (i.e. stimuli) associated with food deprivation. Thus, this approach may help in the development of effective treatments for obesity in humans.

We would like to thank the Editorial Board of Psychopharmacology for agreeing to this project and allowing us to publish this collection of drug discrimination articles that celebrate 30 years of progress on research on the stimulus properties of drugs. This project would not have been possible without their support and guidance. As co-editors we have gained an appreciation for the review and editorial process that is difficult to obtain as authors. Finally, we would like to thank all of the contributors-without them this Special Issue would not have been possible.

\section{References}

Baker LE, Panos JJ, Killinger BA, Peet MM, Bell LM, Haliw LA, Walker SL (2009) Comparison of the Discriminative Stimulus Effects of Salvinorin A and its Derivatives to U69,593 and U50,488 in Rats. Psychopharmacology. doi:10.1007/s00213-0081458-3

Balster RL (1988) Drugs as chemical stimuli. In: Colpaert FC, Balster RL (eds) Transduction mechanisms of drug stimuli. Springer, Berlin, pp 3-11

Colpaert FC (1999) Drug discrimination in neurobiology. Pharmacol Biochem Behav 64(2):337-345
Colpaert FC, Balster RL (1988) Transduction mechanisms of drug stimuli. Springer, Berlin

Colpaert FC, Slangen JL (1982) Drug Discrimination: applications in CNS pharmacology. Elsevier, Amsterdam

Dekeyne A, Millan MJ (2009) Discriminative stimulus properties of the "atypical" antidepressant, mirtazapine, in rats: a pharmacological characterization. Psychopharmacology. doi:10.1007/ s00213-008-1259-8

Glennon RA, Järbe TUC, Frankenheim J (1991) Drug discrimination: applications to drug abuse research. Research Monograph 116. National Institute on Drug Abuse, Rockville

Jewett DC, Hahn TW, Smith TR, Fiksdal BL, Wiebelhaus JM, Dunbar AR, Filtz CR, Novinska NL, Levine AS (2009) Effects of sibutramine and rimonabant in rats trained to discriminate between 22- and 2-hour deprivation. Psychopharmacology. doi:10.1007/s00213-008-1350-1

Koffarnus MN, Greedy B, Husbands SM, Grundt P, Newman AM, Woods JH (2009) The Discriminative Stimulus Properties of Dopamine D2- and D3-Preferring Agonists in Rats. Psychopharmacology. doi:10.1007/s00213-008-1323-4

Kohut SJ, Roma PG, Davis CM, Zernig G, Saria A, Dominguez JM, Riley AL (2009) The Impact of Early Environmental Rearing Condition on the Discriminative Stimulus Effects and Fos Expression Induced by Cocaine. Psychopharmacology. doi:10.1007/ s00213-008-1368-4

Lal H (1977) Discriminative stimulus properties of drugs. Vol. 22 Advances in Behavioral Biology. Plenum, New York

Overton DA (1974) Experimental methods for the study of state dependent learning. Fed Proc 33:1800-1813

Overton DA, Rosecrans JA, Barry H III (1999) Creation and first 20 years of the Society for the Stimulus Properties of Drugs (SSPD). Pharm Biochem Behav 64(2):3347-352

Prus AJ, Pehrson AL, Philibin SD, Wood JT, Vunck SA, Porter JH (2009) The role of $M_{1}$ muscarinic cholinergic receptors in the discriminative stimulus properties of $\mathrm{N}$-desmethylclozapine and the atypical antipsychotic drug clozapine in rats. Psychopharmacology. doi:10.1007/s00213-008-1262-0

Stolerman IP, Shine PJ (1985) Trends in drug discrimination research analysed with a cross-indexed bibliography, 1982-1983. Psychopharmacology (Berl) 86(1-2):1-11

Stolerman IP, Rasul F, Shine PJ (1989) Trends in drug discrimination research analysed with a cross-indexed bibliography, 1984-1987. Psychopharmacology (Berl) 98(1):1-19

Stolerman IP, Samele C, Kamien JB, Mariathasan EA, Hague DS (1995) A bibliography of drug discrimination research, 19921994. Behav Pharmacol. 7:643-668

Thompson T, Pickens R (1971) Stimulus properties of drugs. Appleton-Century-Crofts, New York

Woolf SH (2008) The meaning of translational research and why it matters. JAMA 299(2):211-213

Stolerman IP, Baldy RE, Shine PJ (1982) Drug discrimination procedure: a bibliography. In: Colpaert FC, Slangen JL (eds) Drug discrimination: applications in CNS Pharmacology. Elsevier, Amsterdam, pp 401-441 